American Journal of Pharmaceutical Education 2019; 83 (9) Article 7199.

\title{
RESEARCH
}

\section{A Classroom Activity to Increase Student Pharmacists Confidence in Dealing with the Opioid Epidemic}

\author{
Kevin S. Murnane, PhD, Jill M. Augustine, PharmD, PhD, MPH, Michelle Quesnel, BS, \\ Leisa Marshall, PharmD, J. Grady Strom, PhD \\ Mercer University College of Pharmacy, Mercer University Health Sciences Center, Atlanta, Georgia \\ Submitted June 6, 2018; accepted March 4, 2019; published November 2019.
}

\begin{abstract}
Objective. To implement and assess the impact of a hybrid flipped-classroom activity designed to increase the motivation and confidence of Doctor of Pharmacy (PharmD) students in addressing the opioid crisis.

Methods. Third-professional year student pharmacists were provided with reading material developed by federal agencies and professional pharmacy organizations, as well as Georgia-specific information covering medical amnesty and local resources for opioid-overdose prevention prior to class. They then attended a four-hour classroom session that included hearing a lecture on opioid pharmacology and opioid overdose, viewing training videos, and engaging in extensive discussion. The students voluntarily completed pre- and post-intervention assessments regarding opioid abuse and opioid overdose prevention.

Results. Seventy of the 107 third-year students enrolled in the course completed the pre-intervention assessment (65\% response rate), and 33 of the 70 completed the post-intervention assessment ( $47 \%$ retention rate). The students exhibited a high baseline motivation to assist in combating the opioid crises, but less confidence in their ability to intervene. Significant increases were seen in areas related to student confidence on the post-intervention assessment. Fewer changes were seen in areas related to student motivation.

Conclusion. A "hybrid" flipped classroom activity increased the confidence of student pharmacists in their understanding of the physical and adverse effects of opioids and the application of reversal agents. Increased confidence may support increased intervention.
\end{abstract}

Keywords: pharmacy, opioid, overdose, flipped classroom

\section{INTRODUCTION}

On a daily basis, pharmacists across the United States encounter a large number of patients who have been prescribed opioids, either for acute use or for management of chronic pain. In 2013, US community pharmacies dispensed 207 million opioid prescriptions. ${ }^{1,2}$ Opioid abuse has rapidly become an increasing cause of morbidity and mortality in the United States. Drug overdose has surpassed mortality associated with either motor vehicle accidents or firearms to become the leading cause of accidental death in the United States, driven largely by abuse of prescription opioids. ${ }^{1}$ Around the world, upwards of 36 million people abuse opioids. ${ }^{2}$ More than 90 Americans die daily because of a prescription drug

Corresponding Author: Kevin S. Murnane, Mercer University College of Pharmacy, Mercer University Health Sciences Center, 3001 Mercer University Dr., Atlanta, GA 30341. Tel: 678-547-6290. Fax 678-547-6423. Email: murnane_ks@mercer.edu. or illicit opioid overdose, and over 1,000 Americans are treated in the emergency department because of opioid prescription misuse or abuse. ${ }^{3,4}$ Yearly deaths from overdose have surpassed 60,000, and there were more than half a million deaths from opioid overdose in the United States between 2000 and 2015.,6 Additionally, widespread prescription opioid abuse has become associated with illicit drug abuse. ${ }^{7,8}$ Diversion and abuse of prescribed opioids can result in initiation of heroin use when the cost and availability of prescription opioids become limiting factors. Heroin use among those abusing prescription opioids increased $139 \%$ between $2002-2013,{ }^{9}$ with $80 \%$ of new heroin users having first misused prescription pain medications. ${ }^{10}$

Pharmacists are well positioned to address the opioid crisis. The Centers for Disease Control and Prevention (CDC) recommends an urgent, multifaceted, and collaborative approach to the opioid epidemic., ${ }^{3,11,12}$ The approach should include implementation of $\mathrm{CDC}$ guidelines for 


\section{American Journal of Pharmaceutical Education 2019; 83 (9) Article 7199.}

prescribing opioids for chronic pain, improved use of prescription drug monitoring programs, increased availability of naloxone, and provision of medication-assisted treatment. These are all areas in which pharmacists can have a significant impact in the prevention of deaths resulting from opioids. Pharmacists can use prescription drug monitoring programs to provide external validation and oversight on prescription practices. Pharmacists can counsel patients regarding the use of pharmacotherapies for substance-use disorder, including lifesaving overdose reversal agents. Pharmacists can monitor and contribute to medication-assisted therapy programs for opioid dependence and counsel patients in the benefits and dangers of prescription opioids. Pharmacists are frontline health care providers in key positions and with specific training to intervene in the opioid crisis. Because of the volume of opioid prescriptions with which pharmacists are presented, the general public's access to pharmacists, and pharmacists' reputation as trusted healthcare professionals, pharmacists are in a position to play a critical role in maintaining patient and public safety with regards to opioid use. However, several factors may result in pharmacists being hesitant about becoming involved in the management of opioid abuse and overdose. Fear of legal ramifications, discomfort with assessing the risk factors and symptoms of overdose, insufficient knowledge of the proper use and administration of naloxone, and/or a lack of knowledge or confidence in their ability to make a positive contribution may impede pharmacists from providing appropriate counseling or rendering suitable aid to those who may be at risk of abusing opioids, are abusing opioids, or are experiencing an opioid overdose, or to the families of these vulnerable individuals.

Previous studies have demonstrated that specific training can increase the knowledge and confidence of pharmacists and student pharmacists to intervene in the opioid epidemic. Individuals who self-identified as "naloxone-trained" had high levels of optimism about intervening in the opioid epidemic and low levels of burnout and stigma. ${ }^{13}$ Student pharmacists at Washington State University who had received naloxone rescue training and overdose education from a pharmacist were confident in their capacity to act as trainers in opioid overdose rescue. ${ }^{14}$ As part of a novel, large-group audience-training model, these student pharmacists led a naloxone safety net project to increase awareness of opioid overdose and the availability of naloxone. Likewise, student pharmacists in The Ohio State University College of Pharmacy participated in a naloxone and harm reduction educational program that consisted of a three-part recorded lecture and a hands-on interactive workshop. The student phar- macists reported that this program was beneficial and increased their confidence in this area, with particularly positive reviews of the mock counseling session, handson practice with naloxone delivery devices, and patient case discussions. ${ }^{15}$ This approach used a workshop format to supplement the core curriculum. That curriculum was descriptive and did not utilize a validated or structured feedback survey, but rather offered open-ended responses. The researchers did not conduct pre- and post-intervention assessments to measure whether the live workshop enhanced knowledge, attitudes, confidence, or motivation. In the current study, we have extended this by using an activity that was integrated into the core curricular therapeutic module focused on pain disorders. It consisted of offline foundational material, training videos, live lecture, and group discussion as described later, which was assessed using a comprehensive series of pre- and post- questions subdivided by domain.

In 2016, the CDC issued its first nationwide statement regarding opioid prescribing $\mathrm{s}$, in an effort to slow the opioid abuse epidemic. ${ }^{11}$ Additionally, the US Department of Health and Human Services has identified three priority areas to reduce opioid use disorders and overdose: opioid-prescribing practices, expansion of medication-assisted treatment, and expanded use and distribution of naloxone. Despite advances in available agents and national guidelines, society is unlikely to be able to fully address the opioid crisis until a trained health care workforce that includes pharmacists can bring their knowledge, talents, and professional scope of practice to bear on this issue. Therefore, developing effective methods of training student pharmacists to be effective members of this health care workforce is crucial.

The American Association of Colleges of Pharmacy (AACP) has urged colleges and schools of pharmacy to commit to actions aimed at reducing the public health threat from opioid abuse by using teaching, research, and patient-centered, team-based care that includes but is not limited to preparing every student to provide, administer, and educate others in the appropriate use of life-saving interventions to patients, including family members and others who do not themselves have an opioid use disorder but who may encounter individuals at risk of opiate overdose. ${ }^{16}$ The purpose of this study was to compare students' attitudes, beliefs, and knowledge regarding substance-use disorders; their specific understanding or self-perceived understanding of opioid abuse; their hopefulness for the treatment of opioid abuse; their understanding of and confidence to treat an opioid overdose; and their appreciation of the role of pharmacists in the prevention and treatment of substance abuse and opioid overdose before and after participating in a classroom activity. 


\section{American Journal of Pharmaceutical Education 2019; 83 (9) Article 7199.}

\section{METHODS}

Potential participants were all third-professional year Doctor of Pharmacy (PharmD) students enrolled in a modular course focused on musculoskeletal disorders and pain $(\mathrm{N}=157)$. The Mercer University College of Pharmacy curricula is based on disease-state modules that include four or five week focused, required didactic courses, which include pharmacology, medicinal chemistry, pharmaceutics, and therapeutics. Completion of the pre- and post-intervention survey instruments was completely voluntary. Students were advised that the material covered during the education session would be included on their next examination. Participants had received lectures on the pharmacology of drugs of abuse in their second professional year but had almost no formal education or training on opioid use or abuse. This study was reviewed and approved by the Mercer University Institutional Review Board.

This educational activity was designed and implemented in a required didactic module. The complete activity consisted of material to be reviewed prior to class followed by a classroom session. The pre-class activity included reading material developed by federal agencies and professional pharmacy organizations provided to develop a foundation in the scope of the opioid epidemic and the role of pharmacists in this area. It also included Georgia-specific information covering medical amnesty and local resources for opioid-overdose prevention. Using a traditional lecture format, the classroom session included additional foundational material covering the pharmacology of opioids, medications for opioid-use disorder, and opioid overdose reversal agents. The classroom session also included training videos and extensive discussion on proper naloxone administration, as described in detail later. We describe this overall activity as a "hybrid" flipped classroom activity as some foundational material was provided prior to class and some was provided in class.

At the beginning of the course, enrolled students were invited to voluntarily complete the survey questionnaire, which assessed their attitudes, beliefs, and knowledge regarding substance-use disorders, specific understanding or self-perceived understanding of opioid abuse, hopefulness for the treatment of opioid abuse, understanding of and confidence in the treatment of opioid overdose, and appreciation for the role of pharmacists in the prevention and treatment of opioid overdose. Students were then provided with foundational material on the opioid epidemic via the course learning page, Moodle. Students were asked to review these documents (Table 1) over the following three weeks. We estimated that review of this material would take approximately two hours for students to complete. Assigned components delivered via Moodle for completion outside of the classroom included the Substance Abuse and Mental Health Services Administration's pamphlet on Opioid Overdose, ${ }^{17}$ the CDC Guideline for Prescribing Opioids for Chronic Pain, ${ }^{11}$ the American Pharmacists Association Report on Opioid Overdose Prevention, ${ }^{18}$ and the "ASHP [American Society of Health-System Pharmacists] Statement on the Pharmacist's Role in Substance Abuse Prevention, Education, and Assistance"19 (Table 1). State -specific information covering medical amnesty and local resources for opioid overdose prevention and survival, including recently revised Georgia statutes and a pamphlet from the Atlanta Harm Reduction Coalition, was also included in the pre-class assignment materials. The activity culminated with a four-hour classroom session that included a foundational lecture on the pharmacology of opioids, medications for opioid-use disorder, and opioid overdose reversal agents. During the classroom session, students also watched videos examining addiction, overdose survival, the use of naloxone in opioid overdose, recognizing and responding effectively to overdoses, and personal stories from opioid abusers and people who had survived an overdose (Table 1). Videos presented in the classroom session included Michael Nader: The Value of Drug Addiction Research at TEDxWakeForest $U,{ }^{20}$ which covered the biological basis for addiction; Coming Back from the Dead, ${ }^{21}$ by CNN's Sanjay Gupta, which covered opioid overdose and naloxone; and LIVE! Using Injectable Naloxone to Reverse Opiate Overdose, ${ }^{22}$ by Sawbuck Productions in association with the Chicago Recovery Alliance, which covered how to recognize and respond effectively to an opioid overdose through the use of rescue breathing and naloxone administration (Table 1). Multiple open discussion periods between students and the educator about opioid use and abuse and the important role of pharmacists in the prevention and treatment of opioid overdose occurred throughout the session. Following the educational session, the students were given up to one week to complete a follow-up questionnaire composed of identical questions to the baseline survey.

A questionnaire was developed to assess student pharmacists' attitudes, beliefs, and knowledge regarding substance-use disorders, specific understanding or selfperceived understanding of opioid abuse, hopefulness for the treatment of opioid abuse, understanding of the treatment and confidence in their ability to treat an opioid overdose, and appreciation for the role of pharmacists in the prevention and treatment of opioid overdose. We categorized area 1 as assessing students' attitudes, beliefs, and knowledge regarding the general problem of 


\section{American Journal of Pharmaceutical Education 2019; 83 (9) Article 7199.}

Table 1. Activities Used in a "Hybrid" Flipped-Classroom Approach to Educating Student Pharmacists Regarding the Opioid Epidemic

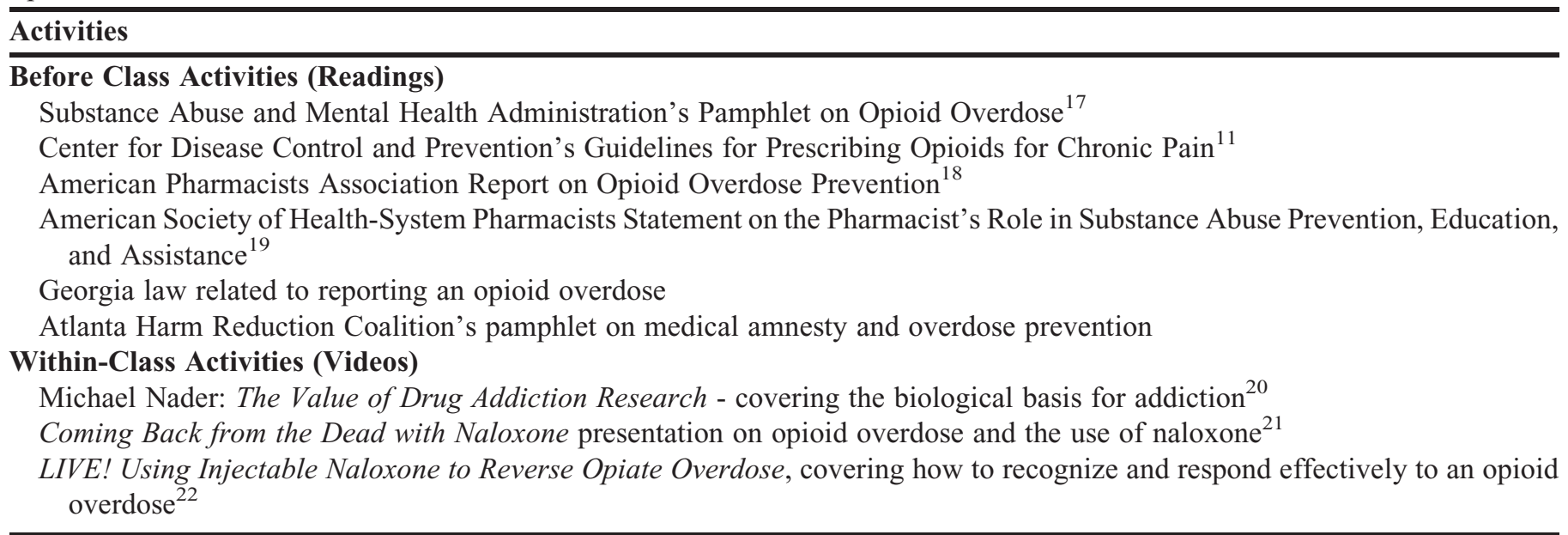

substance-use disorders; areas 3 and 5 as assessing students' motivation to specifically address opioid overdose; and areas 2 and 4 as assessing students' confidence in their ability to address this issue. Each section had four to eight questions. Thirty-four total items were included on the questionnaire: three participant matching questions; eight items on attitudes, beliefs, and knowledge regarding substance-use disorders; five items on understanding or selfperceived understanding of opioid abuse; four items on hopefulness for the treatment of opioid abuse; five items on students' confidence in their ability to treat an opioid overdose; five items on appreciation of the role of pharmacists in the prevention and treatment of substance abuse and opioid overdose; and three program evaluation questions. The questions were created based on questions from previous surveys and adapted or developed by the authors. The questions in the hopefulness for the treatment of opioid abuse section were adapted from the treatment optimism section of the Substance Abuse Attitude Survey, ${ }^{23}$ and the questions regarding attitudes towards substance-use disorders were adapted from the permissiveness section of the Substance Abuse Attitude Survey. ${ }^{23}$ A subset of the questions from these validated surveys were used. Participants were asked to indicate their level of agreement with each of the 34 items using a fivepoint Likert scale $1=$ strongly disagree and $5=$ strongly agree.

The questionnaire was delivered electronically before and after the educational session using the college provided educational learning system (Moodle). Before they received access to the pre-class foundational material on Moodle, participants were given time during a class session early in the course to complete the presession questionnaire. The questionnaire gathered the fol- lowing information to use in matching participants' responses before and after the flipped-classroom session and to maintain the students' anonymity: mother's maiden name, last 4 digits of their cell phone number, and zip code. At the completion of the activity, participants were asked to complete the same questionnaire. The responses of the participants were captured and stored electronically. Differences in responses to survey questions from the pre- to the post-session were evaluated using Wilcoxon signed rank test. Data were analyzed using STATA, version 14.0 (College Station, TX). An a priori alpha level of .05 was used to determine significance.

\section{RESULTS}

Seventy students completed the baseline survey conducted for an initial assessment (107 students were present during the questionnaire administration, response rate $=65 \%$ ). Of these 70 students, 33 completed both the pre- and post-session questionnaires (retention rate $=47 \%$ ). Overall, the flipped-classroom activity was well received by students based on the activity evaluation questions. There was agreement that the activity was beneficial, enjoyable, and should be repeated. Based on one participant's comments, this activity "harbored the development of a compassionate attitude in the students instead of growing the stigma even greater." Moreover, to assess response bias, we compared the respondents (those that responded to the baseline assessment) and nonrespondents (those who did not) in terms of their examination scores on the subsequent test as well as their final examination scores. No significant differences were found between the respondents and nonrespondents on these metrics. 


\section{American Journal of Pharmaceutical Education 2019; 83 (9) Article 7199.}

Students' baseline responses to the eight questions regarding their attitudes, beliefs, and knowledge regarding substance-use disorders are presented in Table 2. Responses to one item ("Addiction is a disease with a biological basis") changed significantly from the pre- to the post-intervention assessment $(p=.018)$, with more participants strongly agreeing with this statement after completing the session (Table 3 ). There were no significant changes in students' responses to the other statements between the pre- and post-intervention period.
Five questions were asked regarding participants understanding or self-perceived understanding of opioid abuse. The baseline responses of the student pharmacists are presented in Table 2. Four of the five questions had significant changes between the preand post-intervention periods (Table 3). More participants agreed in the post-intervention assessment with the item stating that they "understand the most dangerous adverse effects of opioids" (21.2\% compared to $69.7 \%, p<.001)$. Additionally, more participants

Table 2. Student Pharmacists' Baseline Responses to a Survey Regarding Opioid Abuse and Opioid Overdose Prevention $(\mathrm{n}=70)$

Student

Pharmacists

Responses, No.

Survey Item

SD $\quad$ D $\quad$ N A SA

Attitudes, Beliefs, and Knowledge Regarding Substance-Use Disorders

Addiction is a disease with a biological basis

Drug addicts can stop taking drugs through increased effort and mental fortitude

$\begin{array}{lllll}0 & 5 & 11 & 32 & 22\end{array}$

Most drug-dependent persons are unpleasant to work with

$\begin{array}{lllll}3 & 13 & 11 & 34 & 9\end{array}$

Imprisonment is an effective deterrent to subsequent abuse of illicit drugs

$\begin{array}{lllll}1 & 17 & 25 & 25 & 2\end{array}$

I would be willing to work in a pharmacy with a person who has been diagnosed with a drug addiction

Personal use of drugs should be legal in the confines on one's own home

$\begin{array}{lllll}22 & 18 & 16 & 11 & 3\end{array}$

Opioid abuse is largely driven through the desire to recreationally abuse drugs that induce euphoria

$\begin{array}{lllll}6 & 19 & 25 & 11 & 9\end{array}$

I have a friend, family member, or colleague who abuses opioids

$\begin{array}{lllll}32 & 9 & 16 & 11 & 2\end{array}$

$\begin{array}{lllll}4 & 8 & 14 & 32 & 12\end{array}$

$\begin{array}{lllll}30 & 12 & 7 & 7 & 14\end{array}$

Understanding and Self-Perceived Understanding of Opioid Abuse

Heroin accounts for almost all misuse of opioids

$\begin{array}{lllll}17 & 17 & 16 & 18 & 2\end{array}$

I understand the most dangerous adverse effects of opioids

Tolerance develops to all symptoms of opioids

$\begin{array}{llllll}1 & 11 & 7 & 37 & 14\end{array}$

$\begin{array}{lllll}3 & 12 & 24 & 26 & 14\end{array}$

Availability increases the probability of opioid abuse

$\begin{array}{lllll}0 & 5 & 4 & 35 & 26\end{array}$

I feel I know enough about the physical effects of opioid use to carry out my role when working with drug

$\begin{array}{lllll}6 & 17 & 15 & 27 & 5\end{array}$ users

\section{Hopefulness for the Treatment of Opioid Abuse}

Opioid addiction is a treatable illness

Heroin is so addicting that no one can really recover once he/she becomes an addict

An opioid-dependent person who has relapsed several times probably cannot be treated

An opioid-dependent person cannot be helped until he/she has hit "rock bottom"

Understanding of and Confidence to Treat an Opioid Overdose

Only people with an advanced opioid addiction will experience an overdose

I am familiar with the symptoms of opioid overdose

I understand the risk factors associated with opioid overdose

The only appropriate response to a person experiencing an opioid overdose is to call 911

I know how to properly administer naloxone

Appreciation of the Role of Pharmacists in the Prevention and Treatment of Substance Abuse and

Opioid Overdose

Preventing opioid overdose is the exclusive responsibility of prescribers and pain clinics

$\begin{array}{lllll}2 & 0 & 15 & 30 & 23\end{array}$

$\begin{array}{lllll}17 & 28 & 15 & 8 & 2\end{array}$

$\begin{array}{lllll}21 & 30 & 9 & 9 & 1\end{array}$

$\begin{array}{lllll}22 & 25 & 8 & 13 & 2\end{array}$

$\begin{array}{lllll}44 & 20 & 2 & 2 & 2\end{array}$

$\begin{array}{lllll}5 & 18 & 19 & 22 & 6\end{array}$

$\begin{array}{lllll}3 & 13 & 13 & 31 & 10\end{array}$

$\begin{array}{lllll}5 & 17 & 11 & 8 & 3\end{array}$

$\begin{array}{lllll}31 & 17 & 11 & 8 & 3\end{array}$

A professional responsibility of a pharmacist is to educate members of the public in identifying the signs of opioid overdose and the proper administration of naloxone

A professional responsibility of a pharmacist is to participate in public substance abuse education and prevention programs

A professional responsibility of a pharmacist is to discourage prescribing and inventory practices that enable or foster drug abuse behavior

A professional responsibility of a pharmacist is to assist a patient who is experiencing an opioid overdose

$\begin{array}{lllll}28 & 23 & 5 & 11 & 3\end{array}$

$\begin{array}{lllll}2 & 2 & 6 & 25 & 35\end{array}$

$2 \quad 2 \quad 5 \quad 30 \quad 31$

$\begin{array}{lllll}1 & 2 & 5 & 32 & 30\end{array}$

$\begin{array}{lllll}2 & 0 & 6 & 26 & 36\end{array}$ 


\section{American Journal of Pharmaceutical Education 2019; 83 (9) Article 7199.}

Table 3. Significant Changes in Student Pharmacists' Responses to a Survey Administered Before and After Completing a FlippedClassroom Activity Designed to Increase Their Motivation and Confidence to Address the Opioid Crisis

\begin{tabular}{|c|c|c|c|c|c|c|c|c|c|c|c|}
\hline \multirow[b]{2}{*}{ Survey Item } & \multicolumn{5}{|c|}{$\begin{array}{l}\text { Pre-activity Survey } \\
\text { Responses }\end{array}$} & \multicolumn{5}{|c|}{$\begin{array}{l}\text { Post-activity Survey } \\
\text { Responses }\end{array}$} & \multirow[b]{2}{*}{$p$ Value } \\
\hline & SD & D & $\mathbf{N}$ & $\mathbf{A}$ & SA & SD & D & $\mathbf{N}$ & $\mathbf{A}$ & SA & \\
\hline \multicolumn{12}{|l|}{$\begin{array}{l}\text { Attitudes, Beliefs, and Knowledge Regarding } \\
\text { Substance-Use Disorders }\end{array}$} \\
\hline Addiction is a disease with a biological basis & 0 & 3 & 3 & 16 & 11 & 1 & 2 & 1 & 6 & 23 & .018 \\
\hline \multicolumn{12}{|l|}{$\begin{array}{l}\text { Understanding and Self-Perceived Understanding of } \\
\text { Opioid Abuse }\end{array}$} \\
\hline I understand the most dangerous adverse effects of opioids & 0 & 6 & 5 & 15 & 7 & 1 & 0 & 0 & 9 & 23 & $<.001$ \\
\hline Tolerance develops to all symptoms of opioids & 2 & 8 & 11 & 9 & 3 & 25 & 6 & 2 & 0 & 0 & $<.001$ \\
\hline Availability increases the probability of opioid abuse & 0 & 4 & 2 & 18 & 9 & 0 & 2 & 1 & 8 & 22 & .014 \\
\hline $\begin{array}{l}\text { I feel I know enough about the physical effects of } \\
\text { opioid use to carry out my role when working with } \\
\text { drug users }\end{array}$ & 3 & 5 & 9 & 15 & 1 & 0 & 0 & 3 & 16 & 14 & $<.001$ \\
\hline \multicolumn{12}{|l|}{ Hopefulness for the Treatment of Opioid Abuse } \\
\hline $\begin{array}{l}\text { An opioid-dependent person who has relapsed several } \\
\text { times probably cannot be treated }\end{array}$ & 9 & 16 & 4 & 4 & 0 & 17 & 8 & 7 & 1 & 0 & .007 \\
\hline \multicolumn{12}{|l|}{ Understanding of and Confidence to Treat an Opioid Overdose } \\
\hline I am familiar with the symptoms of opioid overdose & 1 & 7 & 8 & 13 & 4 & 0 & 0 & 0 & 10 & 23 & $<.001$ \\
\hline I understand the risk factors associated with opioid overdose & 1 & 6 & 3 & 16 & 7 & 0 & 0 & 0 & 9 & 24 & $<.001$ \\
\hline $\begin{array}{l}\text { The only appropriate response to a person experiencing } \\
\text { an opioid overdose is to call } 911\end{array}$ & 3 & 9 & 6 & 11 & 4 & 11 & 11 & 2 & 6 & 3 & $<.001$ \\
\hline I know how to properly administer naloxone & 12 & 8 & 5 & 6 & 2 & 1 & 0 & 3 & 12 & 17 & $<.001$ \\
\hline
\end{tabular}

strongly disagreed with the statement, "Tolerance develops to all symptoms of opioids," after completion of the activity $(6.1 \%$ pre vs $75.8 \%$ post, $p<.001)$. More participants strongly agreed with the statement that availability increases the probability of opioid abuse (27.3\% pre- vs $66.7 \%$ post-intervention, $p=.014)$. Finally, based on the discussion of the pharmacists' role in opioid abuse, more participants agreed on the postintervention assessment with the statement that they "know enough about the physical effects of opioids to carry out their role as pharmacists when working with drug users" ( $48.5 \%$ pre-intervention vs $90.7 \%$ post-intervention, $p<.001)$.

Participants responded to four questions on their hopefulness for the treatment of opioid abuse (Table 2). Only responses to one question changed significantly from the pre- to post-intervention assessment. A higher percentage of participants strongly disagreed on the postintervention with the statement "an opioid-dependent person who has relapsed several times probably cannot be treated" $(27.3 \%$ pre- intervention vs $51.5 \%$ post-intervention, $p=.007)$.

Five questions were asked to determine participants' understanding of the treatment of and confidence in their ability to treat an opioid overdose (Table 2). Responses to four of the five questions changed significantly from the pre- to the post-intervention assessment (Table 3 ). Significantly more participants strongly agreed with the following three statements on the post-intervention assessment: "I am familiar with the symptoms of opioid overdose" ( $12.1 \%$ vs $69.7 \%, p<.001)$; "I understand the risk factors associated with opioid overdose" $(21.2 \%$ vs $72.7 \%$, $p<.001$ ); and "I know how to properly administer naloxone" $(6.1 \%$ vs $51.5 \%, p<.001)$. More participants disagreed (either strongly disagreed or disagreed) on the post-intervention assessment with the statement, "The only appropriate response to a person experiencing an opioid overdose is to call 911" (36.4\% vs $66.6 \%$, $p<.001)$.

Participants were asked to respond to five questions regarding their appreciation for the role of pharmacists in the prevention and treatment of opioid overdoses (Table $2)$. There were no significant differences between the preand post-intervention assessment on any of the five questions (Table 3).

\section{DISCUSSION}

The purpose of this study was to compare PharmD students' attitudes, beliefs, and knowledge regarding substance-use disorders, their specific understanding or 


\section{American Journal of Pharmaceutical Education 2019; 83 (9) Article 7199.}

self-perceived understanding of opioid abuse, their hopefulness for the treatment of opioid abuse, their understanding of and confidence to treat an opioid overdose, and their appreciation of the role of pharmacists in the prevention and treatment of substance abuse and opioid overdose before and after a classroom activity. Students responded favorably to this activity and approach.

Two of the items assessed the attitudes, beliefs, and knowledge of student pharmacists regarding substanceuse disorders and their hopefulness for the treatment of opioid dependence. At baseline, the student pharmacists had generally positive, compassionate attitudes towards substance-use disorders. Furthermore, approximately one in three student pharmacists reported they knew a person who abused opioids. Student pharmacists were also very hopeful that opioid-use disorder was treatable. These results showed that student pharmacists were positive in their outlook towards people suffering from a substance-use disorder and were hopeful that opioid-use disorder can be effectively treated. The combination of these positive attitudes and the positioning of pharmacists within the healthcare system support the capacities of pharmacists to make a meaningful difference in the opioid crisis, which will be of great benefit to patients and to other healthcare providers as health-care providers are known to also be at risk of opioid abuse. ${ }^{24}$

The classroom activity that we implemented in the present study did impact some of the attitudes, beliefs, and knowledge of student pharmacists regarding substanceuse disorders as well as their hopefulness for the treatment of opioid-use disorder. Student pharmacists must maintain compassionate attitudes towards people suffering from a substance-use disorder as well as have hope that opioid-use disorder can be effectively treated as pharmacists are key health-care providers in the treatment of substance-use disorders. Moreover, negative attitudes in community pharmacists, after controlling for factors such as sex and years of practice, are a predictor of the amount of care pharmacists provide to those with a substance-use disorder. ${ }^{25}$ It would be a great loss to society and the standing of the profession if stigma prevented pharmacists from engaging in an area where they are so greatly needed. Finding that student pharmacists have positive and hopeful attitudes toward the treatment of opioid-use disorder was encouraging. Students' high baseline attitudes may have been why we saw changes in knowledge and confidence but not in attitudes before and after our activity.

The final goal of this activity was to assess student pharmacists' understanding of opioid abuse and their understanding of and confidence to engage in the treatment of an opioid overdose. These are important areas because an increased understanding of substance-use disorders and confidence in the ability to be of assistance has been shown to decrease burnout and stigma and increase the motivation to provide care. ${ }^{13}$ At baseline, student pharmacists reported mixed confidence in their understanding or self-perceived understanding of opioid abuse. Likewise, the student pharmacists reported a less than optimal understanding of and confidence to treat an opioid overdose. These findings suggest that, while student pharmacists are motivated to make a positive contribution to the opioid crisis, they may lack the understanding and confidence to do so.

The implemented classroom activity had a meaningful impact on students' understanding or self-perceived understanding of opioid abuse and overdose, and confidence to engage in the treatment of an opioid overdose. Students also had increased factual knowledge of the effects of opioids. The one item on which the class session did not have a significant impact was whether heroin accounts for all opioid misuse. This may be because the student pharmacists were aware of the problems that may occur with prescription opioids and likely knew that prescription opioids can play a major role in the misuse of opioids. These data suggest that the students gained a greater understanding of the symptoms and risk factors for opioid overdose and gained confidence in how they might be able to handle an opioid overdose or counsel others on how to handle an opioid overdose. While students may have had a general idea that prescription opioid abuse was a major problem prior to this activity, they did not have detailed knowledge of various aspects of the problem. Students seemed to believe that their knowledge of the following had increased: the most dangerous effects of opioids, development of tolerance to opioids, physical effects of opioid abuse, and factors that could increase the probability of opioid abuse. Their high scores on the subsequent summative examination support the accuracy of students' positive self-evaluations on the post-intervention assessment.

Student pharmacists who participated in this study had a high preexisting level of appreciation for the professional responsibility of pharmacists to address the opioid epidemic Therefore, the limited improvement seen in this area following the classroom activity was not surprising. These findings are encouraging as there is a need for increased engagement by pharmacists in addressing the opioid crisis. The CDC suggests an urgent, multifaceted, and collaborative approach, $3,11,12$ and, according to this survey, future pharmacists do believe that it is a professional responsibility to discourage irresponsible prescribing. However, a feeling of professional responsibility is 


\section{American Journal of Pharmaceutical Education 2019; 83 (9) Article 7199.}

most likely to be actualized when the person has the confidence to execute the actions that fulfill that responsibility. Therefore, the students' increased knowledge and confidence in specific areas related to the opioid epidemic after completing the flipped classroom activity were important achievements.

We designed our activity as a "hybrid" flippedclassroom activity in order to allow students to have increased knowledge and awareness of opioid use, abuse, misuse, and treatment with the goal of engendering a deeper comprehension and critical analysis of the material than with pure lecture formats. ${ }^{26-32}$ The results indicate that a "hybrid" flipped-classroom activity can be a useful tool to promote the self-actualization of student pharmacists to meet their potential to curtail the opioid epidemic currently beleaguering the United States. Although student pharmacists' attitudes towards substance-use disorders, hopefulness for the treatment of opioid abuse, and pharmacists' role in the prevention and treatment of overdose did not change significantly, their understanding of and confidence to address opioid abuse and treat/counsel others to treat an opioid overdose did. This is consistent with the established literature that flipped classroom approaches are sound pedagogical models that can result in enhanced student outcomes. ${ }^{33-35}$ For example, a recent study on a satellite campus of the University of North Carolina Chapel Hill College of Pharmacy reported that student pharmacists have positive perceptions of a flipped-classroom approach to pedagogy. ${ }^{33}$ Likewise, the performance of graduate students taking cardiovascular, respiratory, and renal physiology courses increased by approximately 10 basis points when learning is managed with a flipped-classroom approach compared to a traditional lecture model. ${ }^{34}$ These studies have contributed to the growing evidence supporting "flipping" the classroom that is emerging from graduate, medical, and pharmacy educational centers. We designed this activity to maximize time in class for the development of higher-level understanding In-class videos were used as we felt that showing students real life examples of opioid abuse and overdose was important. Moreover, videos are a powerful means of teaching students how to respond in lifethreatening emergency situations. The discussion format afforded the students the opportunity to think through complex issues that they may have not been ready to absorb on their own. The foundational material provided offline before class was used to develop students' appreciation for the scope of the crisis, the role of pharmacists in the crisis, and the changes in prescribing guidelines. The foundational material was designed to inculcate a sense of why this is important to their lives and practice as pharmacists so that they would be motivated to engage in the activity. As we found the largest changes in the areas of knowledge and confidence, we believe that the lecture, videos, and discussion were the most impactful aspects of this activity. However, a detailed assessment of the individual components of the activity is necessary to definitively determine which aspects were the most meaningful. Moreover, this activity may have been effective because it was presented as an integrated whole rather than as a series of separate pedagogical components functioning in discrete ways. This novel pedagogical approach remains to be fully vetted, and additional research is necessary. To the best of our knowledge, this is the first study to describe the use of a flipped-classroom approach to educate health professions students in issues related to the opioid epidemic, as searches of Pubmed and Google Scholar using the search terms "flipped AND classroom AND opioid" resulted in no relevant studies.

This study had several limitations that should be addressed in subsequent research. The study relied on self-reports from the student pharmacists and did not empirically assess learning outcomes related to other pedagogical techniques. This is difficult to address in our curriculum, as there is only one section of each course taught in each year. Follow-up research will compare learning outcomes across year and pedagogical approach. This activity assessed outcomes in a single student pharmacist cohort at a single college of pharmacy. It would be interesting to conduct an organized comparison of approaches across learning context and curricular model. It would also be interesting to compare our "hybrid" flipped-classroom model to a fully flipped classroom as well as to other pedagogical approaches, such as teambased learning, both in terms of student perceptions and student outcomes. Whether the students completed the pre-class materials before coming to the activity was not formally verified, and this could have impacted their overall exposure to the intervention. Furthermore, assessing both how long the reported changes in knowledge and confidence endure and whether they emerge in future cohorts of student pharmacists would be important extensions of the present study.

The study had a lower than expected response rate. This may be attributable to a number of factors. For example, the participants were asked to provide their mother's maiden name, last four digits of a cell phone number, and their zip code for us to use in matching the pre- and post-intervention assessments. Student concerns about providing this information may have reduced the response rate. To address this potential limitation, we determined that there were no significant differences on subsequent examination scores in the course or scores on the final examination between respondents and 


\section{American Journal of Pharmaceutical Education 2019; 83 (9) Article 7199.}

nonrespondents. This suggests that there was little difference in learning or aptitude between these groups. We believe that students' individual learning and aptitude may have impacted response scores in all areas, but particularly in the knowledge domain prior to the activity. If only students from the upper or lower half of the class chose to complete the assessment, their responses may not have reflected the larger student population within the course or within the larger national student pharmacist population. However, other forms of bias, such as personal preconceptions, prior involvement in drug use or drug treatment, having family/friends who suffered from drug abuse/addiction/overdose, may have had important impacts on the results of the assessment. We recognize that this is an important issue and intend to implement strategies to boost the response rate in future studies. We also plan to address some of these questions in future pedagogical research.

\section{CONCLUSION}

Despite the limitations noted, the present study contributes to the pedagogical literature on student pharmacists' knowledge of and attitudes toward combatting opioid abuse and opioid overdose. This study further elucidates the attitudes, beliefs, and knowledge of student pharmacists regarding substance-use disorders, opioid abuse and overdose, whether there is hope for the treatment of opioid abuse, and their professional responsibilities in this area. The "hybrid" flipped-classroom activity that we implemented significantly impacted student pharmacists' knowledge and confidence in their ability to address the opioid crisis. Fewer changes were seen in the assessment areas related to student motivation, most likely because the student participants had high levels of compassion, motivation, and appreciation of their professional roles at baseline. The implementation of training activities that increased student pharmacists' knowledge and confidence to address the opioid crisis, like the one reported in the present study, will allow them to actualize their professional aspirations.

\section{References}

1. Centers for Disease Control and Prevention. National Health Statistics - Injury Related Deaths. https://www.cdc.gov/nchs/fastats/ injury.htm. Accessed April 15, 2018.

2. United Nations Office on Drugs and Crime. World Drug Report. http://www.unodc.org/unodc/en/data-and-analysis/WDR-2012.html. Accessed February 15, 2018.

3. Centers for Disease Control and Prevention. Understanding the Epidemic. 2015.

4. Centers for Disease Control and Prevention. Prescription Opioid Overdose Data. https://www.cdc.gov/drugoverdose/data/

overdose.html. Accessed April 15, 2018.
5. Hedegaard H, Warner M, Minino AM. Drug overdose deaths in the United States, 1999-2016. NCHS Data Brief. 2017(294):1-8. 6. Rudd RA, Seth P, David F, Scholl L. Increases in drug and opioidinvolved overdose deaths - United States, 2010-2015. MMWR. 2016;65(5051):1445-1452.

7. Chang HY, Daubresse M, Kruszewski SP, Alexander GC. Prevalence and treatment of pain in EDs in the United States, 2000 to 2010. Am J Emerg Med. 2014;32(5):421-431.

8. Daubresse M, Chang HY, Yu Y, et al. Ambulatory diagnosis and treatment of nonmalignant pain in the United States, 2000-2010. Medical Care. 2013;51(10):870-878.

9. Drug Enforcement Agency. National Drug Threat Assessment. https://www.dea.gov/docs/DIR-040-17_2017-NDTA.pdf. Accessed April 15, 2018.

10. Jones CM. Heroin use and heroin use risk behaviors among nonmedical users of prescription opioid pain relievers - United States, 2002-2004 and 2008-2010. Drug Alcohol Depend. 2013;132(1-2):95100.

11. Prevention CfDCa. Guideline for Prescribing Opioids for Chronic Pain; 2016.

12. Prevention CfDCa. Increases in Drug and Opioid-Involved Overdose Deaths - United States, 2010-2015. https://

www.cdc.gov/mmwr/volumes/65/wr/mm655051e1.htm. Accessed March 15, 2017.

13. Haug NA, Bielenberg J, Linder SH, Lembke A. Assessment of provider attitudes toward \#naloxone on Twitter. Substance Abuse. 2016;37(1):35-41.

14. Panther SG, Bray BS, White JR. The implementation of a naloxone rescue program in university students. $J A P h A$. 2017;57(2s):S107-S12.e2.

15. Maguire MA, Pavlakos RN, Mehta BH, Schmuhl KK, Beatty SJ. A naloxone and harm reduction educational program across four years of a doctor of pharmacy program. Curr Pharm Teach Learn. 2018;10(1):72-77.

16. Crabtree B, Bootman JL, Boyle CJ, Chase P, Piascik P, Maine LL. Aligning the AACP strategic engagement agenda with key federal priorities in health: report of the 2016-17 Argus Commission. Am J Pharm Educ. 2017;81(8):Article S15.

17. Substance Abuse and Mental Health Services Administration (SAMHSA) U. Opioid Overdose Prevention Toolkit. http:// store.samhsa.gov/product/SAMHSA-Opioid-Overdose-PreventionToolkit/SMA16-4742. Accessed April 24, 2017.

18. Bratberg J, McLaughlin B, Brewster S. Opioid overdose prevention. JAPhA. 2015;55(5):470-476.

19. ASHP Statement on the pharmacist's role in substance abuse prevention, education, and assistance. AJHP. 2016;73(9):e267-270. 20. Nader MA. The value of drug addiction research. American College of Neuropsychopharmacology. https://acnp.org/videos/ michael-nader-the-value-of-drug-addiction-research/. Accessed April 24, 2017.

21. Gupta S. Coming Back from the Dead. CNN. https:// www.cnn.com/videos/bestoftv/2013/11/04/sgmd-naloxone.cnn. Accessed April 24, 2017.

22. Alliance CR. LIVE! Using Injectable Naloxone to Reverse Opiate Overdose. https://www.youtube.com/watch?

$\mathrm{v}=\mathrm{U} 1 \mathrm{frPJ}$ oWtkw\&has_verified=1. Accessed April 24, 2017.

23. Chappel JN, Veach TL, Krug RS. The substance abuse attitude survey: an instrument for measuring attitudes. J Stud Alcohol. 1985;46(1):48-52.

24. Baldisseri MR. Impaired healthcare professional. Crit Care Med. Feb 2007;35(2 Suppl):S106-116. 


\section{American Journal of Pharmaceutical Education 2019; 83 (9) Article 7199.}

25. Matheson C, Bond CM, Mollison J. Attitudinal factors associated with community pharmacists' involvement in services for drug misusers. Addiction. 1999;94(9):1349-1359.

26. Freeman S, Eddy SL, McDonough M, et al. Active learning increases student performance in science, engineering, and mathematics. Proc Natl Acad Sci. 2014;111(23):8410-8415. 27. Roberts TE. Delivering tomorrow's curriculum. Med Teacher. 2012;34(7):519-520.

28. Sharma N, Lau CS, Doherty I, Harbutt D. How we flipped the medical classroom. Med Teacher. 2015;37(4):327-330.

29. Wakabayashi N. Flipped classroom as a strategy to enhance active learning. Kokubyo Gakkai zasshi J Stomatological Soc, Japan. 2015;81(3)-82(1):1-7.

30. Onda M, Takagaki N. Approach to evidence-based medicine exercises using flipped teaching: introductory education for clinical practice for 4th-year pharmacy students. Yakugaku Zasshi: $J$ Pharmaceutical Soc Japan. 2018;138(5):645-647.

31. Mortensen CJ, Nicholson AM. The flipped classroom stimulates greater learning and is a modern 21 st century approach to teaching today's undergraduates. J Animal Sci. 2015;93(7):3722-3731.

32. Ward M, Knowlton MC, Laney CW. The flip side of traditional nursing education: a literature review. Nurse Educ Pract.

2018;29:163-171.

33. McLaughlin JE, Griffin LM, Esserman DA, et al. Pharmacy student engagement, performance, and perception in a flipped satellite classroom. Am J Pharm Educ. 2013;77(9):Article 196. 34. Tune JD, Sturek M, Basile DP. Flipped classroom model improves graduate student performance in cardiovascular, respiratory, and renal physiology. Adv Physiology Educ. 2013;37(4):316-320. 